\title{
Mt Owen Mine barrier pillar
}

\author{
W.D. Bartlett Thiess Pty Ltd, Australia \\ I.H. Clark GEONET Consulting Group, Australia \\ D.E. McCormack Thiess Pty Ltd, Australia \\ G.D. Johnson Thiess Pty Ltd, Australia
}

A.N. Brown Thiess Pty Ltd, Australia

\begin{abstract}
As the Mt Owen Mine progressed, turning from mining in a south westerly direction to a south easterly direction, in-pit dumping constraints demanded an innovative solution to prevent potential lowwall instabilities. An in situ rock pillar was designed to retain waste spoil, this was termed the 'barrier pillar'. Measuring $270 \mathrm{~m}$ high and over a kilometre long, consisting of over $40 \mathrm{Mbcm}$ of in situ rock and retaining in excess of $160 \mathrm{Mm}^{3}$ of waste spoil. It is considered that the barrier pillar is the world's largest in situ rock mass earth retaining structure.

Stability of the barrier pillar was governed by the weak tuffaceous layers within the coal that have caused historical instabilities. Analyses of the barrier pillar have been undertaken throughout the mine life; as the mine design evolved, so did the pillar design. The initial analysis was undertaken using a two-dimensional limit equilibrium model with multiple sections. Due to the complex nature of the geological structure, a subsequent analysis was undertaken using FLAC3D. Three pillar designs were analysed through thirteen stages of mining in order to predict rock mass behaviour through the proposed mining sequence, identify potential instability and determine the most appropriate pillar design.
\end{abstract}

Automated prism monitoring and two brands of slope stability radars were used to monitor displacement of the barrier pillar. No significant displacement was detected during mining prompted an investigation into maximising coal recovery. Two-dimensional limit equilibrium analysis was used to assess the design. Comparisons were made between the successfully mined goodbye cut and the original FLAC3D modelled pillars to ensure no additional modelling was required.

\section{Introduction}

The B5 C1E barrier pillar (pillar) has been incorporated into the mine shell in order to retain the waste rock spoil that has been dumped in Pit B while the adjacent Pit $\mathrm{C}$ is mined. The mine plan at the Mt Owen Mine (Mt Owen) is dump constrained with limited floor space available to build dumps on and further constraints due to instability of the lowwall. The pillar is intended to retain approximately $160 \mathrm{Mm}^{3}$ of waste rock spoil. Measuring $250 \mathrm{~m}$ high and over a kilometre long, it is constructed from approximately $40 \mathrm{Mm}^{3}$ of in situ rock. It is potentially the largest in situ earth retaining structure ever excavated. Figure 1 shows the location of the pillar as excavated.

This paper is a culmination of reviews of previous studies, geotechnical analysis carried out on site, three-dimensional geotechnical analyses, and the stability of the pillar during mining. It also details further analyses to allow the mining of a final cut (goodbye cut).

The current mining operation at Mt Owen began in 1993. It is unknown when the original concept for the pillar came into the mine plan. The mine design evolved over the years; so too did the pillar design. The first known stability assessment of the pillar was completed in 2003 and was revisited regularly since this time. 


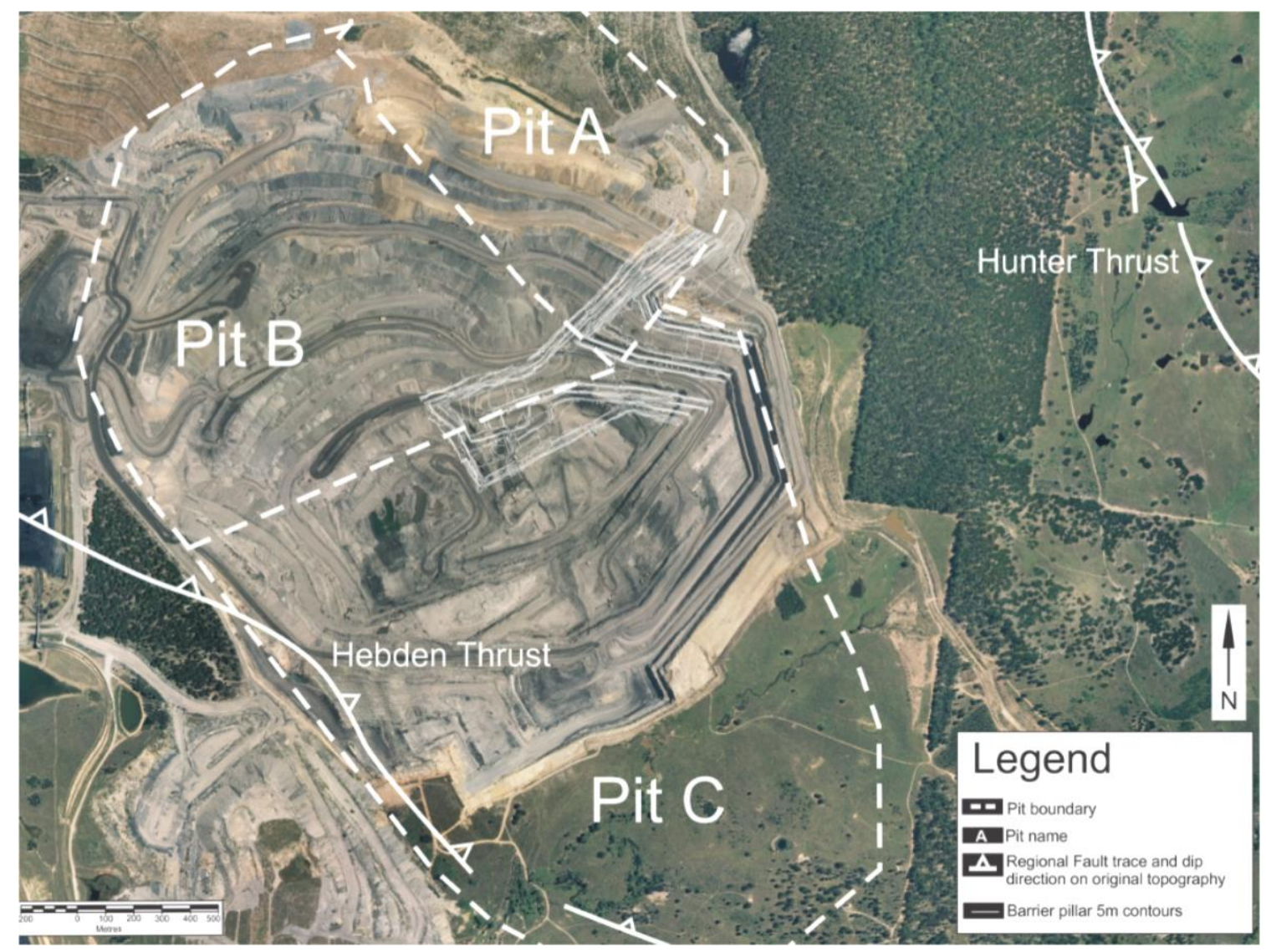

Figure 1 Aerial image of Mt Owen Mine

Geotechnical assessments and on site analyses completed in 2008 concentrated on ensuring the pillar would retain the maximum volume of dump material possible. Adjustments to the pillar dimensions were then made to ensure that an adequate Factor of Safety (FS) was achieved. Due to the three-dimensional nature of the pillar, lowwall and dump profile it was considered worthwhile carrying out three-dimensional geotechnical analysis of the pillar to better understand the factors driving stability. Monitoring of the pillar during mining was carried out using an automated prism monitoring system and slope stability radars. Mining of the pillar was carried out through three mining blocks.

Based on monitoring and performance data obtained a final cut, termed the goodbye cut, was planned to take advantage of low strip ratio coal. The analysis for this work was completed while considering the previous response to mining, additional geotechnical data and the existing three-dimensional model.

\section{Geological and geotechnical setting}

The Mt Owen Mine reserve consists of 15 seam groups from the Foybrook Formation of the Wittingham Coal Measures in the Singleton Subgroup. The seams generally comprise multiple splits and varying thicknesses totalling over 70 minable coal plies. Figure 2 illustrates the in situ coal seams and interburden that constitute the pillar.

Coal interburden consists of interbedded mudstone, siltstone and sandstone with occasional beds of conglomerate, base of weathering is normally within 10 to $15 \mathrm{~m}$ of the surface, fresh rock is grey to light grey, bedding varies from sub-horizontal to very steeply dipping, thin to very thick, weak to high strength. Discontinuities are generally widely to very widely spaced.

Thinly bedded tuff bands are common within the Mt Owen coal seams. Many of these are weathered to a weak, soft clay. 


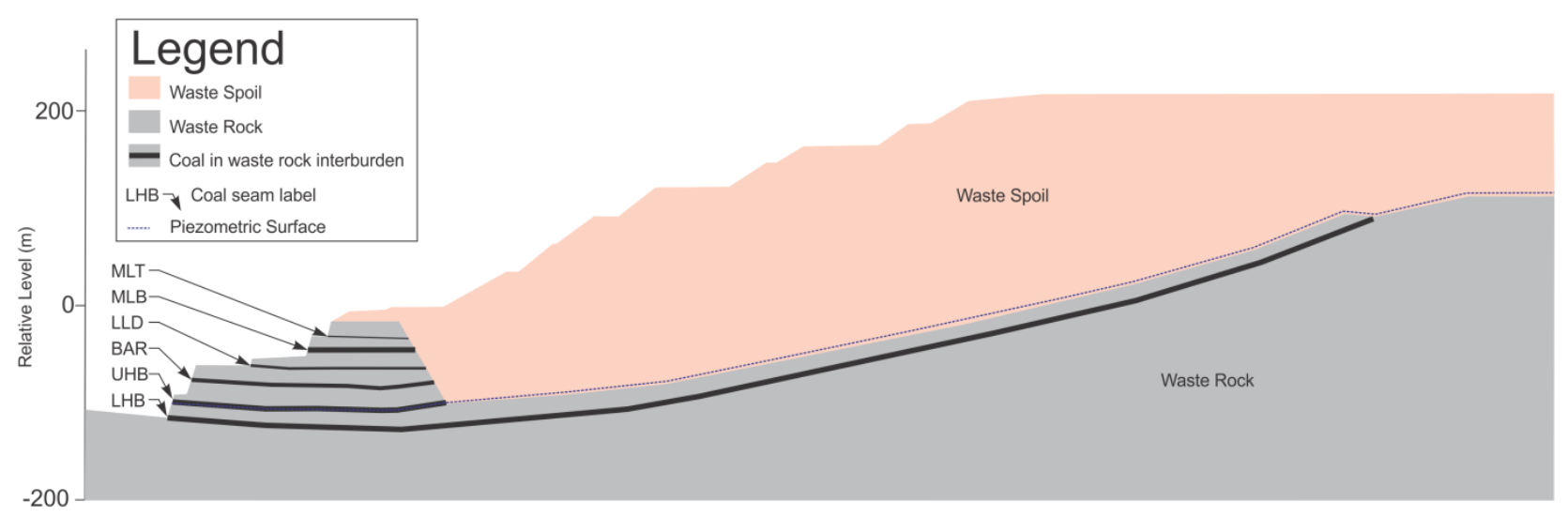

Figure 2 Section 6 through pillar and retained waste spoil

Mt Owen is situated between two large regional thrust faults; the Hunter Thrust to the North West and the Hebden Thrust to the South East (Figure 1). As a result of the compressional environment, coal seam dip varies from horizontal to vertical with an average dip of $22^{\circ}$. The deposit is dissected by several large folds and fault splays causing significant localised folding of the strata.

The B Pit was mined in a westerly direction with a lowwall mined down to the Upper Hebden Coal Seam and a highwall up to $250 \mathrm{~m}$ high. The pillar is situated at the toe of the B Pit highwall in a syncline as the floor of the C Pit raises up on the Lower Hebden floor in to a dome structure to the south (refer to Figure 3).

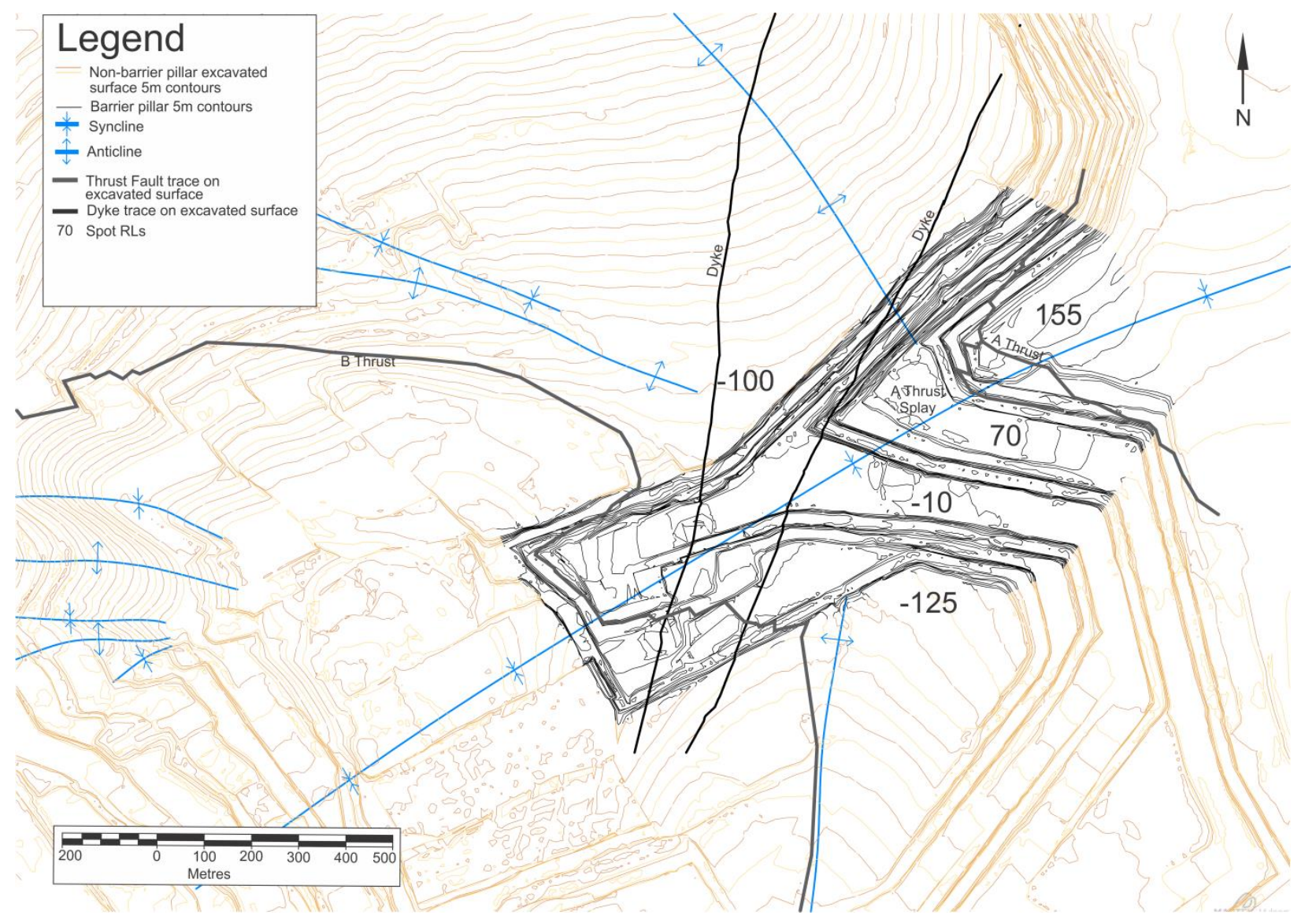

Figure 3 Barrier pillar, final excavated surface and geologic structure 


\section{$3 \quad$ Pillar and spoil dump slope design}

Assessments carried out in the preliminary stages of design indicated that with controls in place the concept would be possible. The pillar was required to retain more material than the preliminary designs due to limited floor space to build dumps. As the mine design and the expected dump capacity were determined, it was considered that further work needed to be carried out to assess the stability of the pillar design. The analysis was undertaken on 15 pit shell pillar with the waste dumps loaded to maximum capacity.

\subsection{Stability of pillar rock slopes}

Any structurally-controlled rockfall hazard was expected to be controlled by wall design. The pillar is a total of $280 \mathrm{~m}$ in height; the wall design incorporates $30 \mathrm{~m}$ high batters angled at $75^{\circ}$ with $15 \mathrm{~m}$ wide catch benches. Haul roads are incorporated into the design as a bench 45 to $60 \mathrm{~m}$ wide at least every $60 \mathrm{~m}$ in elevation. There was expected to be an increased potential for failure associated with the external corners. Multi-bench failures were thought to be unlikely, and any rockfalls would be controlled by the catch benches.

\subsubsection{Major structures}

Several major structures intersect the pillar as illustrated in Figure 3 and detailed below. The A thrust intersects the pillar at RL135 and dips into the buttress of the pillar. It was not expected that there would be any adverse effects on stability due to the favourable orientation of the A thrust.

- The A thrust splay was mapped daylighting out of the northern wall of the upper section of the pillar buttress. The splay was measured to dip $32^{\circ}$. Little of this structure was known prior to its exposure due to mining. This area remains under constant monitoring.

- The B thrust was expected to dip in a north easterly direction through the lower section of the pillar. Several failures occurred on the west facing, western end of the pillar associated with fault intersecting the wall.

- There are two dykes that intersect the pillar. They are sub vertical and strike to the north east (Figure 3). Structurally controlled failure associated with the dykes was considered to be unlikely. The orientation of the dykes is not unfavourable; however the persistence of the structures could affect the integrity of the rock mass through the narrow central section of the v15 pillar.

\subsubsection{Rock mass failure}

An additional stability analysis was carried out on site to maximise the volume of spoil which could be retained by the pillar. This was completed by utilising GALENA ${ }^{\circledR}$ Limited Equilibrium Slope stability software. Previous analysis of lowwall stability including back-analysis indicated that any failure would likely occur along weak clay seams within the Lower Hebden (LHB) coal seam (Figure 2). The LHB was not mined across the lowwall of the B Pit leaving the weak seam in situ $17 \mathrm{~m}$ below the lowest mined seam the Upper Hebden (UHB). The seams dip at approximately $17^{\circ}$. The LHB was mined in C pit causing the potential critical failure surface to daylight at the toe of the pillar. It was critical that the stability of pillar was ensured.

\subsubsection{Piezometric conditions}

It was assumed during modelling that the piezometric surface was 2 metres above the base of the spoil and UHB floor interface (Figure 2). The UHB and LHB within the pillar were assumed to be saturated. Drilling and placement of piezometers after mining the $B$ pit and prior to developing the $C$ pit confirmed this. As the pillar was open-ended to the west water could drain to the west and prevent excessive pour water pressure within the pillar or the retained spoil. 


\subsubsection{Material properties}

The material properties used for analysis have been developed from previous stability analyses and back-analysis of previous failures. Previous failures used for back-analysis include the $15 \mathrm{Mm}^{3}$ lowwall failure in the $B$ pit and numerous other failures in both pit $A$ and pit $B$. It was determined that weathered tuff bands within the LHB/UHB coal seams were the cause of these failures. The material properties are listed in Table 1.

Table 1 Material properties

\begin{tabular}{cccc}
\hline Material & $\mathbf{c}^{\prime}(\mathbf{k P a})$ & $\boldsymbol{\phi}^{\prime}\left({ }^{\circ}\right)$ & $\gamma\left(\mathbf{k N} / \mathbf{m}^{\mathbf{3}}\right)$ \\
\hline Spoil unsaturated & 30 & 28 & 18 \\
Spoil saturated & 15 & 23 & 20 \\
Fresh rock normal & 450 & 42 & 24 \\
Fresh rock fault zone 50-30 m & 135 & 38 & 24 \\
Fresh rock fault zone 30-0 m & 290 & 40 & 24 \\
Weak clay seams & 0 & 12.5 & 24 \\
Fresh coal & 35 & 35 & 15 \\
\hline
\end{tabular}

\subsection{Two-dimensional stability analyses}

The major analysis on the pillar was conducted using pit shell v15. The v15 pillar had a narrow section through the central portion. The western end was wider to retain waste spoil material dumped on the western side of the pit, with this wider section known as the foot of the pillar. Previous analyses carried out indicated that failure would most likely occur along a weak clay seam within the LHB coal, and the analysis was carried out with this in mind.

Conventional 2D analysis would orientate the section downslope at the surface. As detailed information regarding the orientation potential failure surfaces was available, two styles of analysis were carried out. The first were analyses carried out with parallel sections perpendicular to the pillar. The second style was analyses carried out down the direction of dip of the LHB floor. The down dip run of analyses were Section 1,2 and 3, sections ran perpendicular to the pillar were 4, 6, and 8. Section 12 is to the west of the pillar. The location of these sections is illustrated in Figure 4. A critical FS was derived from the analysis of each section. Results of analyses are presented in Table 2.

Table 2 Results of analyses v15 pillar design

\begin{tabular}{cccc}
\hline Section & FS & Width of Crest & Description of Failure Path \\
\hline Section 1 & 3.04 & $172 \mathrm{~m}$ at RL -70 & Through LHB \\
Section 2 & 1.07 & $108 \mathrm{~m}$ at RL -20 & Through LHB \\
Section 3 & 1.11 & $46 \mathrm{~m}$ at RL -20 & Through LHB \\
Section 4 & 1.11 & $50 \mathrm{~m}$ at RL -55 & Through LHB \\
Section 6 & 1.02 & $66 \mathrm{~m}$ at RL -20 & Through LHB \\
Section 8 & 1.23 & $46 \mathrm{~m}$ at RL -20 & Through LHB \\
Section 12 & 2.27 & $73 \mathrm{~m}$ at RL -95 & Through LHB \\
\hline
\end{tabular}




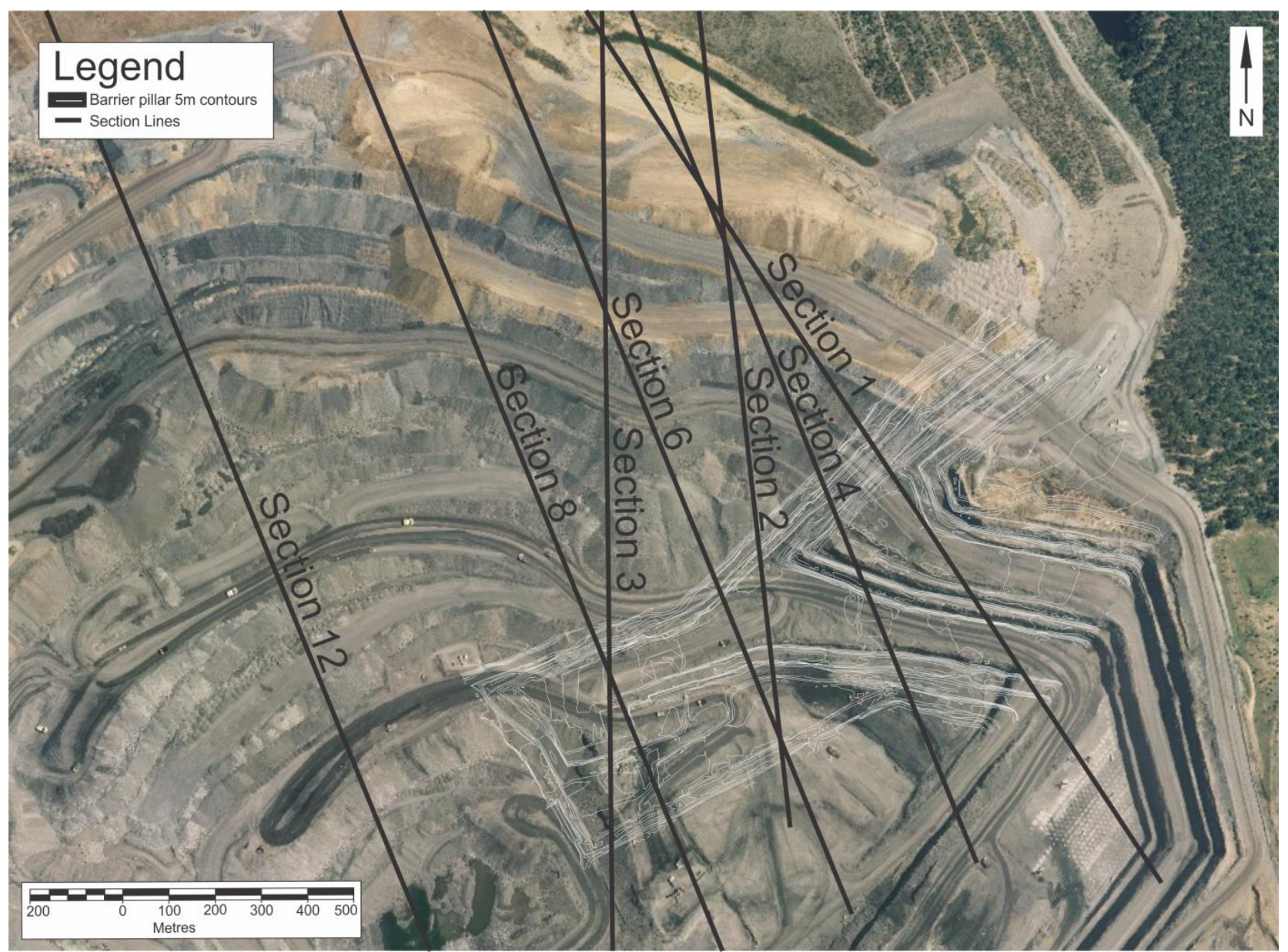

Figure 4 Final pillar and 2D analysed section lines

Figure 5 illustrates the results of the two-dimensional analysis. The FS is seen to be below the required 1.2 through the central narrow section of the pillar.

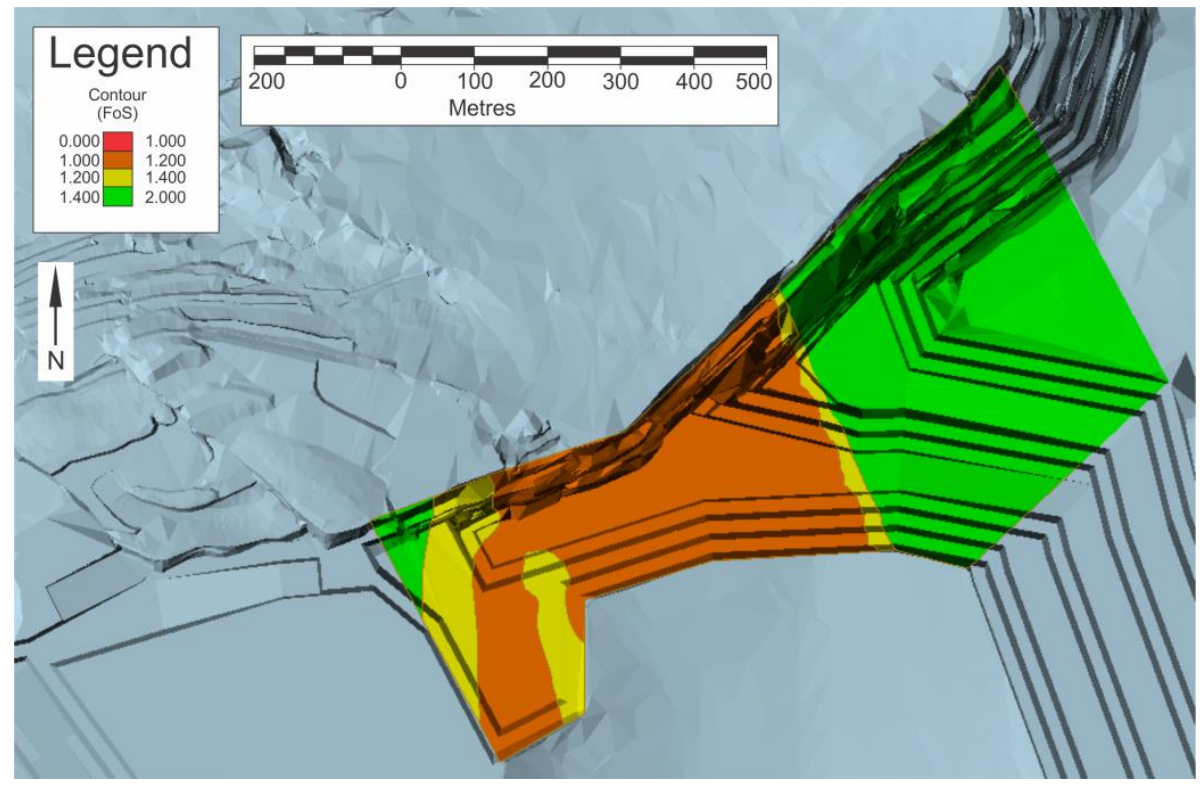

Figure 5 Pillar v15 two-dimensional Factor of Safety contoured 


\subsubsection{Redesign of pillar}

From the analysis carried out it was evident that the critical failure mechanism would be the weak clay seams within the LHB coal seam. The pillar sits in a low point of a syncline which increases stability as the dip failure surface decreases and reverses. To improve the stability of the pillar by increasing the width, the mass of the pillar increases and the length of the failure surface on the up dip leg of the syncline increases resistance to failure.

The required FS for the pillar was 1.2. Analyses were carried out to assess the critical width of the pillar to achieve a FS 1.2. The increase in widths of the pillar compared to v15, are described in Table 3 . The pillar designed with a FS 1.2 from limit equilibrium analysis became known as v12.

Table 3 Pillar width analysis

\begin{tabular}{cccc}
\hline Section & Below RL & v15 & v12 \\
\hline Section 4 & Crest RL -55 & $56 \mathrm{~m}$ & $90 \mathrm{~m}$ \\
& Mid-level RL -20 & $160 \mathrm{~m}$ & $290 \mathrm{~m}$ \\
& Base RL -128 & $352 \mathrm{~m}$ & $427 \mathrm{~m}$ \\
Section 6 & Crest RL -20 & $78 \mathrm{~m}$ & $195 \mathrm{~m}$ \\
& Base RL -120 & $192 \mathrm{~m}$ & $305 \mathrm{~m}$ \\
Section 8 & Crest RL -30 & $80 \mathrm{~m}$ & $220 \mathrm{~m}$ \\
& Mid-level RL -65 & $205 \mathrm{~m}$ & $240 \mathrm{~m}$ \\
& Base RL -117 & $312 \mathrm{~m}$ & $312 \mathrm{~m}$ \\
\hline
\end{tabular}

\subsubsection{Coal loss}

The v12 pillar contained an additional $6 \mathrm{Mm}^{3}$ of in situ rock and $1.1 \mathrm{M}$ tonnes of ROM coal compared to the v15 pillar, with a Strip Ratio of 4.4. The volume of coal left in situ represents a significant loss in coal production and associated revenue. Any additional work required to minimise this loss in coal production could be easily justified.

\subsection{Discussion of results}

The results from the v15 pillar indicated a low FS through the central narrow section of the pillar. The FS of the Eastern buttress (Section 4) is low, but to the east of this the buttressing effect improves the stability. The FS of the western end (Foot) is adequate. This correlation was indicated in both the parallel sections and the down dip sections. West of the buttress the FS improves as the LHB coal dips deep into the bottom of the pit.

The study of the down dip sections highlighted the fact that the placement of the foot at the lower end of the pillar has a beneficial effect on the stability. The stability of the narrow section of the pillar under two-dimensional analyses was marginal, however it is anticipated that the down dip movement of the bulk of material would concentrate forces on the buttress or the foot of the pillar. The 12 design increased the width of the central narrow section of the v15 pillar. This sterilised $1.1 \mathrm{M}$ tonnes of ROM coal.

\subsection{Three-dimensional geotechnical modelling of the pillar}

Initial 2D limit equilibrium analyses increased the size of the pillar substantially. Analyses indicated that with the existing understanding of material properties the stability of the 12 pillar would be satisfactory. However, if there was a reduction in the material properties for any reason, the determined FS could drop below the required 1.2. To fully appreciate the three-dimensional (3D) nature of the lowwall and larger structures a 3D geotechnical model of the stability was created in FLAC3D. 


\subsubsection{Objectives of 3D analysis}

Three different pillar designs were assessed and are explained as follows:

- $\mathrm{v} 12$ is the most conservative design, based on 2D limit equilibrium stability assessment producing a pillar with a Factor of Safety of FS 1.2.

- $\mathrm{v} 15$ is the most slender design that results in greatest coal recovery but which, according the 2D limit equilibrium stability analysis has a lower than desired FS.

- v21 is an intermediate design where a relatively slender upper pillar has a wider buttress at lower levels in the $\mathrm{C}$ Pit and incorporates a ramp design.

The objective of the analysis was to provide a geotechnical assessment of the rock mass behaviour during mining of the pillar. The following objectives were addressed:

- Simulate the proposed mining sequence to a final depth of $\mathrm{RL}-130 \mathrm{~m}$.

- Predict overall rock mass behaviour around the pillar.

- Target areas of instability.

- Identify operational hazards at successive stages of proposed mining sequence.

- Recommend which of the three pillar designs will be stable.

In order to achieve these objectives the scope of the geotechnical modelling project involved building a 3D stress model of the B pit lowwall area so that the full impact of spoil loading could be assessed during proposed mining sequences in $C$ Pit. The purpose of the modelling was to predict the response of the rock mass in the C1E pillar during successive stages of mining so that key mechanisms of behaviour could be identified.

The scope of work involved the following steps:

1. Review and assess the geological/structural conditions in B and C Pit areas.

2. Construct an appropriate 3D geotechnical model which includes:

- Stratigraphy with thrust induced folding.

- Major structures (faults, dykes, shear planes, etc.).

○ Rock mass fabric (bedding and jointing).

- Appropriate material properties.

○ In situ stress field.

- Mining geometry/extraction sequencing.

3. Identify potential mechanisms and controls on instability within the pillar and spoil dumps and establish the role of critical stratigraphic horizons and structural geology.

4. Identify specific hazards that may develop during final stages of mining which may affect safe and productive mining schedules.

5. Recommend a pillar design which will ensure stable and safe working conditions while maximising coal recoveries.

\subsubsection{Model geology}

The structural geology model including coal seams, A and B thrust faults, and two dykes. The groundwater piezometric level within the Upper Hebden was also incorporated. 


\subsubsection{Model properties}

The estimates of rock mass strength for each of the rock units in this study were based on previously established properties from back-analysis using two-dimensional methods on site. The properties were subsequently verified in a previous three-dimensional geotechnical model of the western end of the B Pit.

Rock mass properties under normal circumstances have been determined to be those of Fr Rock normal in Table 1. The properties of Fr Rock FZ 30-0 m and Fr Rock FZ 50-30 m are indicative of a rock mass becoming increasingly fractured adjacent to a fault zone. In this case these decreasing rock mass properties have been implemented as a result of the decrease in strength associated with disturbance caused as a result of folding, lack of confinement and blast damage. It may be that this degrading of rock mass strength in this instance is in excess but it is necessary to appreciate the magnitude of the decrease in FS associated with the decrease in rock mass properties.

Weak clay bands have been logged in coal seams including the Barrett (BAR), UHB and LHB. Material properties (refer to Table 1) for these clay bands were derived by testing and back-analysis. The persistence of the clay band in the LHB resulted in the B4 failure. The GALENA models have been constructed and analysed on the basis that potential failure mechanisms would develop along the clay bands within the coal seams. Based on these material properties a new suite of parameters was calculated for the intact rock $\left({ }^{*} \mathrm{r}\right)$ and corresponding rock mass jointing $\left({ }^{*} \mathrm{jt}\right)$ for each lithostratigraphic member as input to the 3D model. These values are summarised in Table 4.

Table 1 Material properties for the principal rock mass units

\begin{tabular}{|c|c|c|c|c|c|c|c|c|c|}
\hline Rock & $\begin{array}{c}K \\
(\mathrm{GPa})\end{array}$ & $\begin{array}{c}\mathbf{G} \\
(\mathrm{GPa})\end{array}$ & $\begin{array}{l}\text { Density } \\
\left(\mathrm{kg} / \mathrm{m}^{3}\right)\end{array}$ & $\begin{array}{l}\text { Coh_r } \\
\text { (MPa) }\end{array}$ & $\begin{array}{c}\text { Fri_r } r \\
\left({ }^{\circ}\right)\end{array}$ & $\begin{array}{l}\text { Ten_r } \\
\text { (MPa) }\end{array}$ & $\begin{array}{l}\text { Coh_jt } \\
\text { (kPa) }\end{array}$ & $\begin{array}{l}\text { Frijit } \\
\left({ }^{\circ}\right)\end{array}$ & $\begin{array}{l}\text { Ten_jt } \\
(\mathrm{KPa})\end{array}$ \\
\hline BAR interburden & 2.62 & 1.968 & 2500 & 8.99 & 42 & 6.67 & - & - & - \\
\hline BAR coal & 1.90 & 0.85 & 1583 & 0.30 & 50 & 0.15 & 1.4 & 25 & 1.4 \\
\hline UHB interburden & 1.80 & 0.87 & 2550 & 0.45 & 42 & 0.40 & 1.4 & 35 & 1.4 \\
\hline UHB coal & 1.90 & 0.85 & 1583 & 0.30 & 50 & 0.15 & 1.4 & 15 & 1.4 \\
\hline LHB interburden & 1.80 & 0.87 & 2550 & 0.45 & 42 & 0.40 & 1.4 & 35 & 1.4 \\
\hline LHB coal & 1.90 & 0.85 & 1583 & 0.30 & 50 & 0.15 & 1.4 & 12.5 & 1.4 \\
\hline Basement & 2.40 & 1.20 & 2600 & 9.00 & 43 & 3.00 & - & - & - \\
\hline
\end{tabular}

\subsubsection{Initial stress conditions}

The in situ pre mining stress field would have been substantially influenced by the geological history of the area. In particular the presence of thrust faults and folding in the immediate area suggest that the major compressive force is orientated in the direction normal to the trace of the thrusts, i.e. east-west. This is also consistent with measured borehole breakout orientation. The minor principal stress direction would most probably be directed normal to this in the north south direction. Stresses in the vertical direction would have been substantially reduced due to uplift and weathering of the landscape. It is assumed that these will be entirely due to gravity without a tectonic component added. Thus the vertical stress field is initialised to increase with depth according to the following relationship:

$$
\sigma_{\mathrm{V}}=\gamma z
$$

Where:

$$
\begin{aligned}
& \sigma_{v}=\text { the vertical stress. } \\
& v \quad=\text { the unit weight of the overlying rock. } \\
& z \quad=\text { the depth below surface. }
\end{aligned}
$$


The magnitude of the two principal horizontal stresses is initialised based on the following stress ratios:

$$
\begin{aligned}
& \sigma_{\mathrm{EW}}=1.5 \sigma_{\mathrm{V}} \\
& \sigma_{\mathrm{NS}}=2.0 \sigma_{\mathrm{V}}
\end{aligned}
$$

Where:

$$
\begin{aligned}
& \sigma_{\mathrm{EW}}=\text { Stress in an east-west orientation. } \\
& \sigma_{\mathrm{NS}}=\text { Stress in an north-south orientation. }
\end{aligned}
$$

\subsubsection{Pillar mining sequence}

The model was equilibrated with the initialised stress field prior to mining so as to establish the pre-mining stress field. The response of the rock mass to the proposed mining sequence was made by simulating the mining profiles at quarterly increments, totalling fourteen stages.

\subsubsection{Presentation of results}

The extent and geological complexity of the model present a substantial task for understanding, interpreting and presentation of results. The approach was taken to interrogate the results within the three-dimensional model and to project these onto two-dimensional vertical planes. Two planes were selected for presentation orientated:

a. To intersect the barrier pillar normally at its narrowest section.

b. To cut the barrier pillar longitudinally.

In order to identify geotechnical conditions in the rock mass, plots of the following data were analysed for each of the three designs:

- Geology.

- Stress induced damage.

- Contours of displacement magnitude.

- Displacement vectors.

- Velocity vectors and contours.

- Unbalanced force vectors.

These were used as a basis for assessing the geotechnical conditions in the final design. These results were then analysed in relation to the likely conditions that could manifest during mining. The stability was assessed in relation to the deformation and displacement rates through successive stages of mining. FS relies on knowing the 'strength' of the material, defined as:

$$
\mathrm{FS}=\text { Strength } / \text { Stress }
$$

In engineered materials, (materials with uniform or known strength), this concept is acceptable. But in complex geological environments where there are multiple materials with internally varying properties it is impossible to define a single value FS for use as a design criterion. In a jointed rock mass the localised FS must be calculated for both the intact rock material and also for the potential for shear to develop on the joint or bedding planes.

In the definition of localised FS when the stress is equal to the strength (FS $=1$ ) then the material will be in a state of imminent failure. However, the term 'failure' is quite emotive and can be misinterpreted because earth (i.e. frictional) materials may exist in this critical state while still remaining stable; but this will only occur if a viable unstable mechanisms of deformation can develop. In fact, an intact spoil dump or rock slope presents a far greater risk to safety than the same immediately following the formation of a slip 'failure' because the 'failed' slope has actually reverted to a more stable state. 
The purpose for including this digression is to indicate that a rock mass may well exists at a FS less than the global design criterion (for example, $\mathrm{FS}=1.2$ for $2 \mathrm{D}$ limit equilibrium analyses) and still be stable. Local stability becomes an issue when:

1. Local deformation increases to magnitudes greater than the joint spacing.

2. Displacement rates do not stabilise following a mining stage.

In order to assess the stability of the proposed barrier pillar designs, the results of the plots of the following:

a. Displacement magnitude contours.

b. Stress induced damage.

c. Local FS of rock / dump matrix.

d. Local FS of rock mass joints.

e. Global FS.

f. Histories of displacement at selected locations within the barrier pillar.

Consideration of issues 1 and 2 together with plots $(a)$ to $(f)$ inclusive thus becomes the $3 \mathrm{D}$ equivalent to the $2 \mathrm{D}$ global FS.

The histories of displacement were monitored throughout the simulated mining sequence. In order to monitor the displacements at different levels within the pillar, histories of displacement were tracked at the narrowest section of pillar in each of the overburden geological units.

The overall deformation of the barrier pillar was monitored in the LHB overburden. Histories were not monitored further east in the pillar because the pillar width increases and is effectively buttressed by the C1E side wall.

\subsubsection{Results of three-dimensional modelling}

For all of the scenarios the results of the analysis indicate there is extensive stress induced damage (Figure 6). At the crest of the pillars stress conditions were tensile. In all pillars the spoil slope was subjected to localised shearing and down slope displacement. For all versions of the Pillar the unbalanced force vectors are largest at the exposed face in the C Pit. All models indicated shearing at the base of the spoil that extends into the pillars along the UHB.

There was displacement observed in the UHB and LHB in all scenarios, which corresponded to shearing on planar interfaces. The displacement vector plots indicate that lateral translation of the pillar would occur by sliding within weak clay bands within the UHB and LHB. The deformation magnitude increases with elevation in stratigraphic profile with maximum displacement at the crest.

The displacement contour plots clearly indicate that the dykes allow areas adjacent to them to move at varying rates. The largest deformations are indicated at the crest measured at $2.5 \mathrm{~m}$ for $v 12$ and $3.5 \mathrm{~m}$ for both v 21 and v15 pillars. The 1.5 m contour extended as deep as the Barrett in v12 and the LHB in both the v21 and v15 pillars. The stress condition and stress-induced damage follows a similar trend to that of the displacement contours for all pillars. The global FS for spoil material indicate that the spoil slope is in a yielding state, with the global FS below 1.

In order to assess the potential for failure to develop by the mechanism of spoil loading, displacement histories were tracked at positions in the pillars. There are distinct increments in displacement associated with successive stages of mining. These displacements all stabilise after each stage. Displacement tracers indicate that although rate of displacement increases toward the final stage of mining upon completion it reverts back to a background rate. 

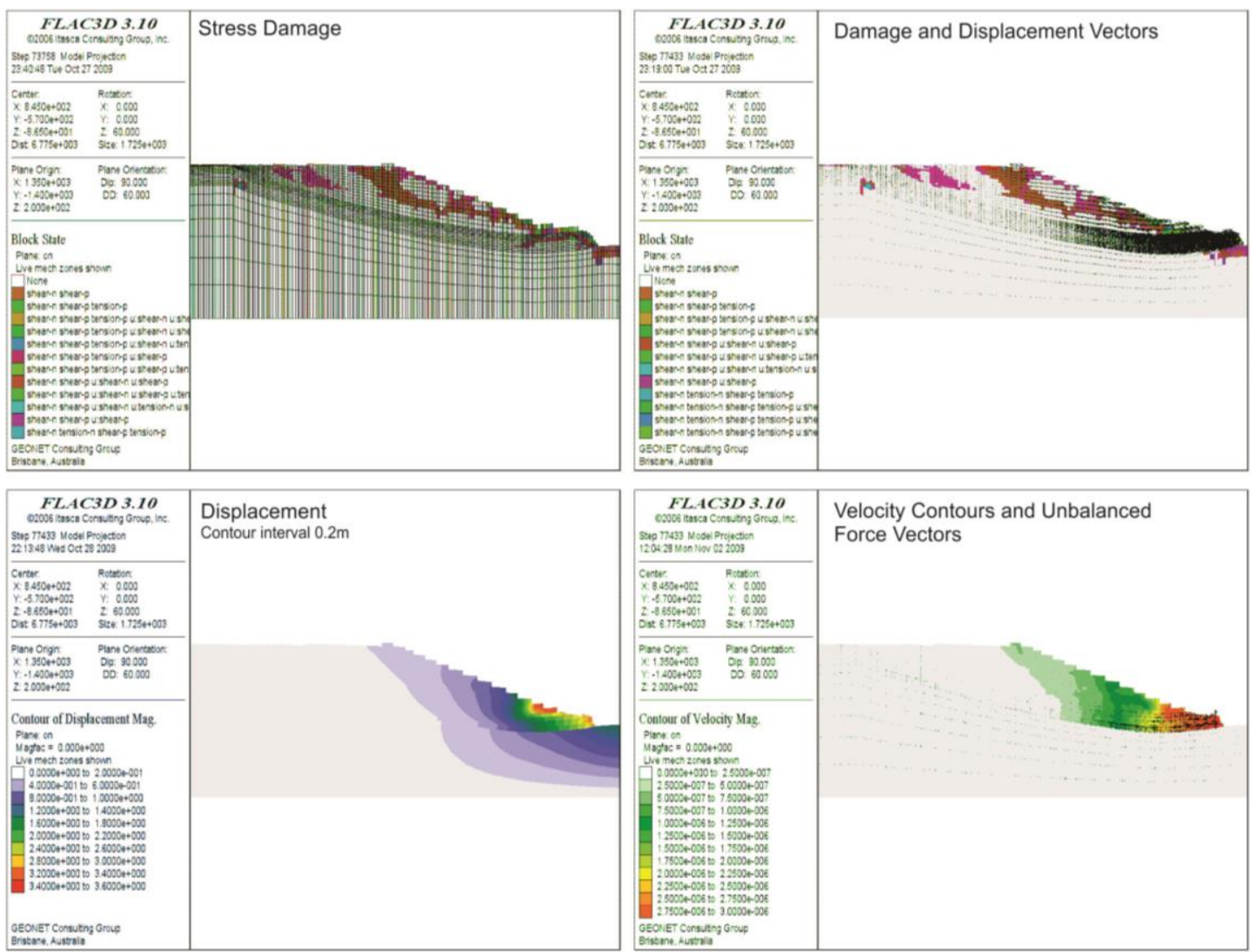

Figure 6 Pillar v12 FLAC3D plots

Table 5 Displacement of pillars at the crest and base

\begin{tabular}{ccc}
\hline Pillar & Base LHB & Crest \\
\hline v12 & $1.4 \mathrm{~m}$ & $2.54 \mathrm{~m}$ \\
v21 & $1.6 \mathrm{~m}$ & $3.1 \mathrm{~m}$ \\
v15 & $1.8 \mathrm{~m}$ & $3.2 \mathrm{~m}$ \\
\hline
\end{tabular}

Table 6 Displacement rates for each of the pillars modelled

\begin{tabular}{ccccc}
\hline Pillar & $\begin{array}{c}\text { Initial } \\
\text { (mm/day) }\end{array}$ & $\begin{array}{c}\text { Final Stages of } \\
\text { Mining } \\
\text { (mm/day) }\end{array}$ & $\begin{array}{c}\text { After Completion } \\
\text { of Mining } \\
\text { (mm/day) }\end{array}$ & $\begin{array}{c}\text { Maximum } \\
\text { Displacement } \\
\text { (mm/day) }\end{array}$ \\
\hline $\mathrm{v} 12$ & 0.22 & 2.59 & 0.22 & 1.4 \\
$\mathrm{v} 21$ & 0.22 & 4.56 & 0.29 & 1.6 \\
$\mathrm{v} 15$ & 0.22 & 4.72 & 0.22 & 1.8 \\
\hline
\end{tabular}

\subsubsection{Discussion of results of three-dimensional modelling}

Results were reported as a result of stress induced damage, FS in rock matrix and on joints and deformation. There were distinct differences in the predicted deformation behaviour of the three pillar designs. However, the overall rock mass behaviour and pillar stability of the three designs is similar. Based on a local FS criterion it was shown that all three of the final pillar were in a state of yield. However, analysis of the displacement history plots suggests that uncontrolled movement (i.e. failure) does not occur. 
In complex geological environments where there were multiple materials with internally varying properties, it is impossible to define a single value FS for use as a design criterion. And since frictional materials may exist in a critical state $(F S=1)$ while still remaining stable, it must be concluded that the use of global Factor of Safety as a design criterion is extremely limiting. Following this it is recommended that geotechnical analysis take into consideration that stability only becomes an issue when:

1. Local deformation increases to magnitudes greater than the joint spacing indicating a reduction to residual joint strength.

2. Displacement rates do not stabilise following a mining stage.

The important observation to consider was that although displacement rates increased with each mining stage, the rate then reduced after each stage. The stress damage indicated that joints would start to dilate and initiate spalling of material. This would be more prolific adjacent to and between the dykes in the lower section of the pillar. The results indicate that all three of the proposed pillar designs will be metastable. The designs were expected to move, the rock mass condition deteriorate, and rocks fall out of the exposed faces.

\section{$4 \quad$ Final pillar design}

After all analysis was complete it was recommended that the v21 design be implemented with the option to review stability after mining to the pit floor. If conditions were good an option was available to mine the additional portion down to the 15 version. Some alterations were made to the ramp configuration across the crest of the pillar with a switchback at the foot and ramp down on the downslope side. This design was compared to the v21 version, considered similar in geometry, and the model was not required to be re-run.

\section{$5 \quad$ Mining the pillar}

\subsection{Wall conditions}

The eastern buttress of the pillar is a bull nose intersected by the A Thrust Splay dipping out of the wall at $32^{\circ}$. The splay is also intercepted by a sub vertical dyke adjacent to the corner. The intersection of these structures and the exposed corner has caused deteriorating conditions and failure. Weathered material at the crest of the slope has also caused failure. This has caused significant interruption to the RL120 ramp below. The failures were managed by installing a significant catch windrow and times limiting the ramp to one lane due to the potential for rockfalls. After considerable effort to clean up failed material and regular inspections this is again a two lane ramp for heavy vehicles and limited access from light vehicles. Normal wall conditions have prevailed for the remainder of the pillar during mining. Occasional isolated rockfalls have been noted but contained by catch benches.

\subsection{Pillar deformation}

During the final excavation of the pillar a slope stability radar was used in combination with the existing prism monitoring system to measure displacement of the pillar. Fortunately the Pillar did not show any signs of mass movement during the mining process. The unit was alarmed for movements over a significant area of exposed face - at least tens of meters squared - to monitor for the movement predicted in the modelling process and not localised rockfall which is managed by catch benches and mining procedures.

Once the target pit floor had been reached and no signs of deformation had been measured it was thought that the material properties in the pillar model may have been overly conservative. The weak clay bands were assumed to be continuous in the model. Observations at the toe of the pillar indicated that areas of tuff had weathered to clay as expected and other areas had remained unweathered.

The improved material properties of the weak clay seams is expected to have reduced movement and associated damage to the in situ rock mass of the pillar. This reduced the extent of damage to the exposed rock faces and spalling of the walls. 


\section{$6 \quad$ Goodbye cut}

The pillar's response to mining was better than expected, so a Goodbye Cut (GBC) was thought to be feasible provided further analyses were completed. The GBC was to target Middle Liddell, Lower Liddell and Barrett seams now easily accessible and low strip ratio coal. The proposed GBC represented $1.7 \%$ of the total volume of the pillar.

Further analyses including kinematic and two-dimensional limit equilibrium analyses were completed. Back analysis of the pillar as mined was carried out and found to be comparable to previous two-dimensional analyses. The existing FS was 1.1 suggesting conservative parameters given the pillar displayed no indications of stress, spalling or cracking. The GBC design was comparable to the v15 pit shell modelled in the three-dimensional analysis, although v15 had all seams being mined to the floor.

The toe of the pillar was buttressed by approximately $25 \mathrm{~m}$ depth of spoil placed on the dry and competent floor. This buttressed potential failure planes in the LHB and UHB that were modelled as the critical failure surfaces. Due to the lack of deformation during the initial mining of the pillar, mining the GBC was carried out using the prism monitoring system only.

\section{Conclusion}

Two-dimensional analysis of the v15 pillar indicated that the pillar needed to be larger to retain the material that was to be dumped behind it. A v12 pillar was designed with the intention of increasing the FS to FS 1.2. This redesign significantly increased the volume of material required to remain in situ including sterilising significant coal reserves. An intermediate pillar v21, was designed between the v15 and v12 pillars.

Due to the complex geology of the pillar, a three-dimensional geotechnical model was developed and analysed for stability and likely causes of instability and deformation. Of the three different scenarios analysed it was recommended that the intermediate pillar v21 be mined with the option to go back and mine to the smaller v15 pillar.

The three-dimensional analysis indicated that it would be expected that the pillar would deform by movement on weak clay seams within the lower coal seams. This would also cause damage throughout the in situ rock mass of the pillar and would be expected to culminate into increased spalling of the exposed faces and mass movement of the pillar on those weak clay seams. It was not expected that the mass movement would culminate in catastrophic failure.

Monitoring of the pillar indicated that mass movement did not occur and very little evidence of any increased rate of spalling was observed during the initial mining of the v21 pillar. The weak clay seams that were anticipated to govern the stability of the pillar were less weathered than expected. This mitigated the deformation of the pillar. Back-analysis on the v21 pillar indicated that mining a goodbye cut to a lesser extent than the v15 pillar was viable option. The final coal gained from the v12 pillar to the final pillar mined was 850,000 ROM tonnes. This was completed without any significant deformation of the pillar and no incidents.

The design and analysis of the pillar was undertaken to a considerable level of detail and due diligence. This enabled the barrier pillar to be mined to optimal productivity without major incident.

\section{Acknowledgement}

The authors thank John Simmons, Sherwood Geotechnical and Research Services, for technical support and due diligence; and lan Clark, GEONET Consulting Group, for three-dimensional FLAC3D modelling and recommendations. 